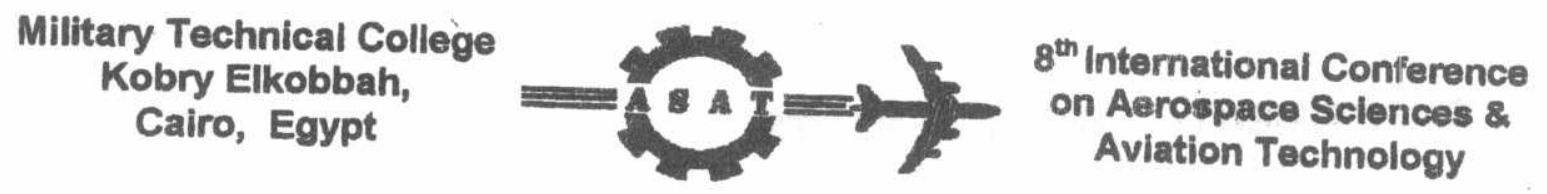

\title{
PLASMA COAXIAL DISCHARGE EFFICIENCY
}

\author{
E.A. MEHANNA
}

\begin{abstract}
A coaxial discharge system with negative central electrode has been used to study the plasma current sheath and the ejected plasma parameters. Results showed that the plasma sheath velocity reached $5 \times 10^{5} \mathrm{~cm} / \mathrm{s}$ at the muzzle. The ejected plasma velocity in the expansion chamber varied with position $z$ according to the relation $V=k \cdot z^{-0.5}$, while the temperature and the density changed as: $T=T_{0} \cdot z^{-1.8}$ \& $N=N_{0} \cdot z^{-1.2}$, respectively. It has been detected that the plasma current sheath and the ejected plasma are accompanied with an induced axial magnetic field, which indicated that the plasma rotates within its propagation.

The input energy from the capacitor bank to the coaxial discharge system was $196 \mathrm{~J}$, (Joule), the energy gained by the plasma as kinetic energy was $17 \mathrm{~J}$, while the plasma internal energy was $5.6 \mathrm{~J}$. Hence $8 \%$ of the energy was gained as a kinetic drift of the plasma.
\end{abstract}

\section{KEY WORDS}

Plasma, coaxial discharge, efficiency.

\section{INTRODUCTION}

In coaxial discharge a plasma, current sheath is formed at the breach and axially accelerated by Lorentz force $(\mathrm{Jr} \times \mathrm{B} \phi)$ [1,2,3]. There is a current limit [4], which depends on the plasma parameters. When the discharge plasma current exceeds such limit a current disruption occurs. The shape of the sheath within the coaxial electrode has been obtained theoretically and it was in close agreement with experimental results $[3,5,6]$. The ejected plasma from the coaxial gun has been applied in different fields where some applications need cold plasma with high kinetic energy while others require hot plasma with moderate drift velocity. A previous study investigated the plasma coaxial gun efficiency for both drift and random velocity of investigated with relation to the initial discharges. 


\section{EXPERIMENTAL ARRANGEMENTS}

The plasma gun system consists of two concentric stainless steel coaxial cylindrical electrodes and a $6.25 \mathrm{~kJ}$ capacitor bank, figure (1). The inner electrode has $200 \mathrm{~mm}$ length and $33 \mathrm{~mm}$ diameter while the outer electrode has $240 \mathrm{~mm}$ length [8] and 66 $\mathrm{mm}$ diameter. A ceramic disk is fixed at the breach and the muzzle is connected to an expansion chamber with $150 \mathrm{~mm}$ diameter and $230 \mathrm{~mm}$ length. The system is fixed with vacuum pump and gas leakage control unit. Diagnostic instrumentation includes electric and magnetic probes, capacitor voltage divider, and pick-up loops.

\section{RESULTS AND DISCUSSION}

For capacitors charging voltage of $10 \mathrm{kV}$, the discharge current reached its peak value of $28 \mathrm{kA}$ within $6.8 \mathrm{ks}$. Magnetic probe and a miniature Rogovsky coil showed that the plasma sheath is formed at the start of the discharge within $50 \mathrm{~ns}$. The pick up coil around the outer electrode measures the induced axial magnetic field attached to the plasma current sheath [9]. The time of arrival of the plasma current sheath at several positions in the axial phase is shown in figure (2).

The velocities of the plasma current sheath, from the derivative of position - time relation, are shown in figure (3). The pick-up loop measurements showed that the velocity of the plasma current sheath increases from the start of the discharge up to $2.8 \mu \mathrm{s}$ to reach $10^{65} \mathrm{~cm} / \mathrm{s}$ then decreases to a constant velocity of $0.46 \times 10^{6} \mathrm{~cm} / \mathrm{s}$ up to the muzzle. Figures ( $2 \& 3$ ) show differences between the measurements of the pickup coil and the magnetic probe. This is due to that the pickup coil measures the axial magnetic field of the rotated current while the magnetic probe detects the azimutal magrietic field at the back of the current sheath. This can be used in determination of the current sheath thickness of the plasma current variation with its motion figure (4).

The plasma current sheath was ejected from the muzzle with velocity of $0.46 \times 10^{6}$ $\mathrm{cm} / \mathrm{s}$, figisre (3). Electric probe and magnetic probe measured the ejected plasma velocity variation with distance. Results showed, figure (5), that the ejected plasma flow velocity decreased within propagation in the expansion chamber according to the relation:

$$
V=k \cdot z^{-0.5}
$$

The ejected plasma temperature and density at the muzzle, obtained from the single probe characteristic curves, are $7.5 \mathrm{eV}$ and $8 \times 10^{13} \mathrm{~cm}^{-3}$, respectively.

The plasma electron temperature and density variations with position are shown in figure (6).

The results showed that:

$$
T=T_{0} \cdot z^{-1.8} \quad \& N=N_{0} \cdot z^{-1.2}
$$


The deposited energy by the capacitor bank sheath motion to the muzzle, from voltage and current measurements, was $196 \mathrm{~J}$. The calculated kinetic energy gained by the sheath was $17 \mathrm{~J}$, while the plasma internal energy was 5.6J.

\section{CONCLUSION}

In a coaxial plasma gun the plasma current sheath structure investigations showed that it rotates around the coaxial electrode. Its velocity increased by the increase of the Lorenz force then decreased due to the increase of its mass to reach a constant value of $5 \times 10^{5} \mathrm{~cm} / \mathrm{s}$ up to the muzzle. The estimated kinetic energy the plasma drift of the plasma. This low efficiency of the input energy was gained as kinetic radiation, and the ionization of the Argon gas.

The plasma propagation velocity in the expansion chamber follows the relation: $V=k \cdot Z^{0.5}$. This indicates that the ejected plasma sheath expands
adiabatically in a cylindrical form.

\section{REFERENCES}

[1] Marshall J. ; J. Phys. Of Fluids, vol. 3, p. 134(1960).

[2] Mather J.W. ; J. Phys. Of Fluids, vol. 3,p. 366 (1965).

[3] Masoud M.M., and Soliman H.M. ; ARE-AEE, Rep. 268 (1981). [4] E.A. Mehanna, A.S.Giogi and H.F. El Afifi ; First international on Electrical

[5] Tsagas N.F., Mair G.L.R., and Prinn A.E., J. Phys. D, vol. 11, p. 1283(1974).

[6] Abas S. and El-Fayoumy M.K.K. ; Plasma Phys., vol. 19, p. 415 (1977).

[7] Fillipov N.V. ; Soviet J. Plasma Phys., vol. 9, p. 406 (1983).

[8] TahaH.F. ; M. Sc. Thesis, Military Technical College (1997).

[9] Soliman H.M. and Masoud M.M. ; Physica Scripta, vol. 50, p. 406 (1994). 


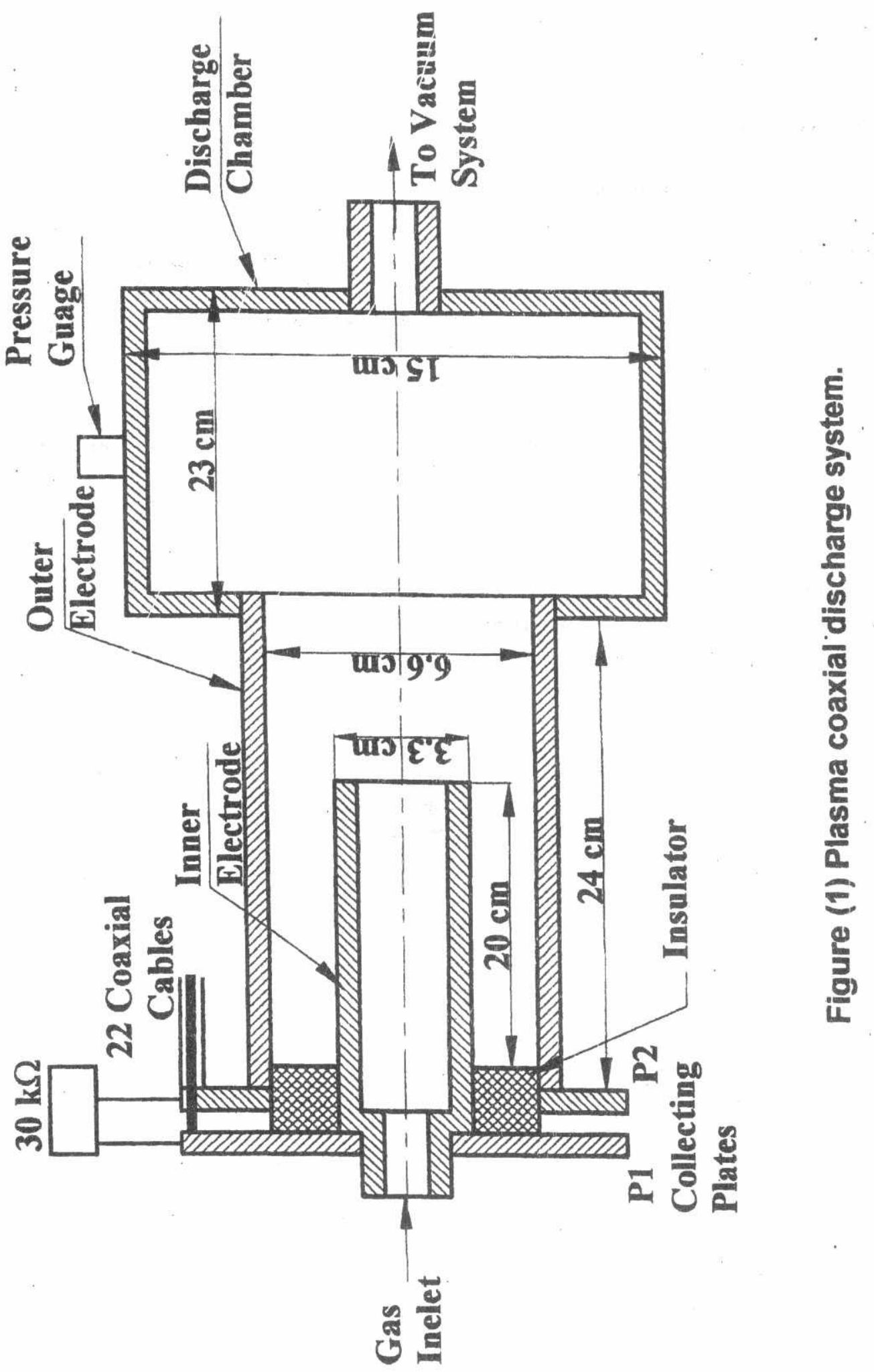




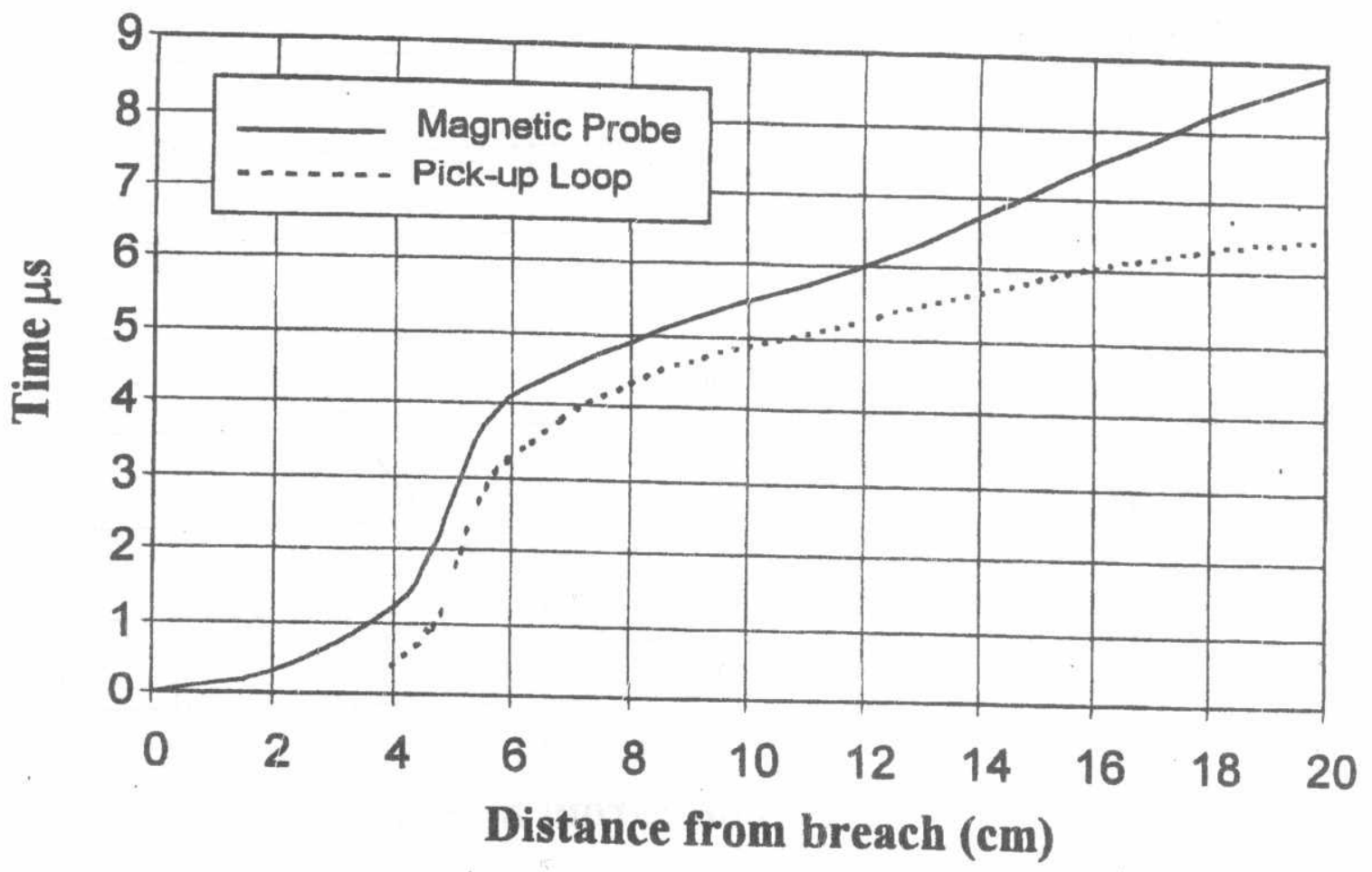

Figure (2) Current sheath position-time relation.

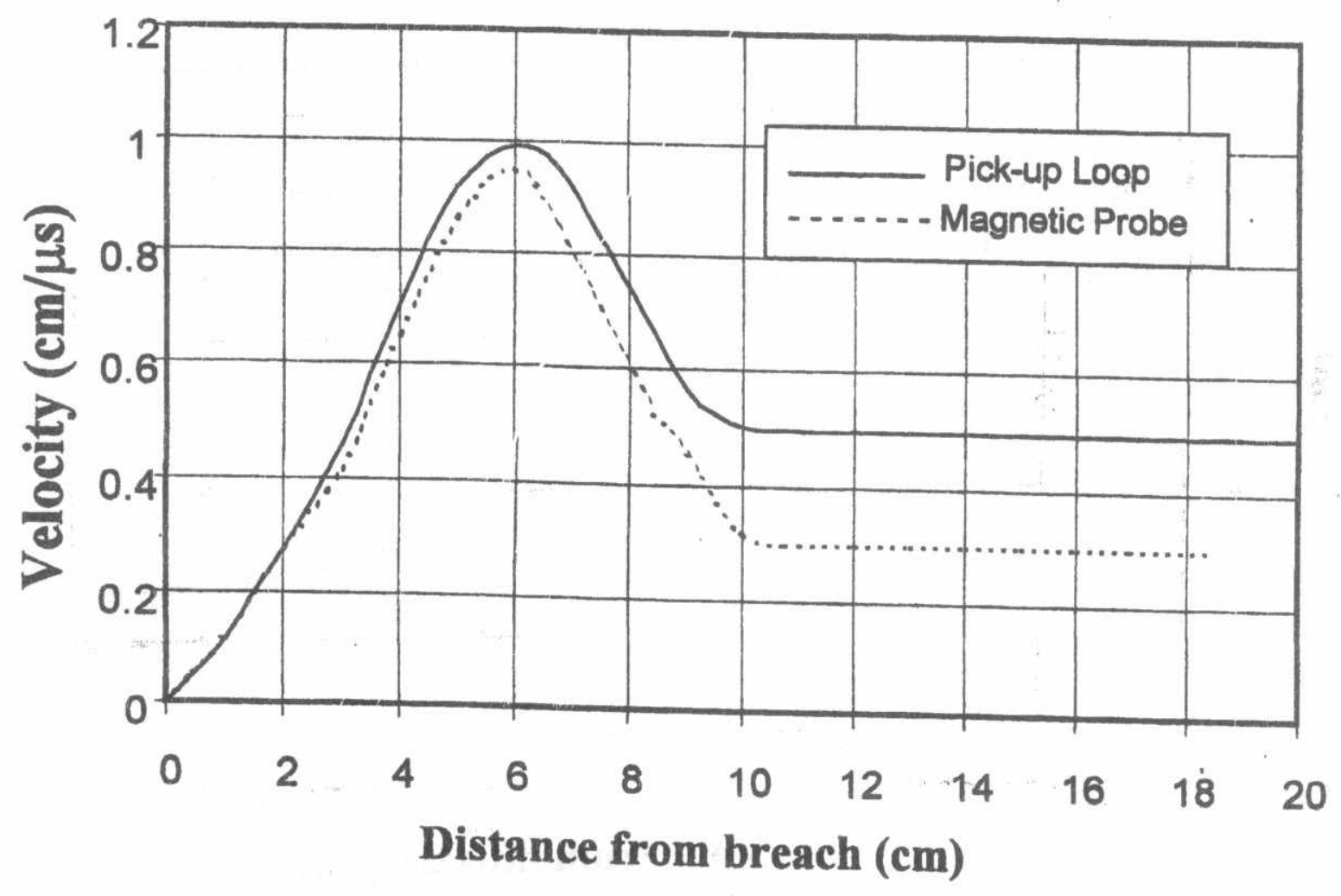

Figure (3) Plasma current sheath velocity versus position. 


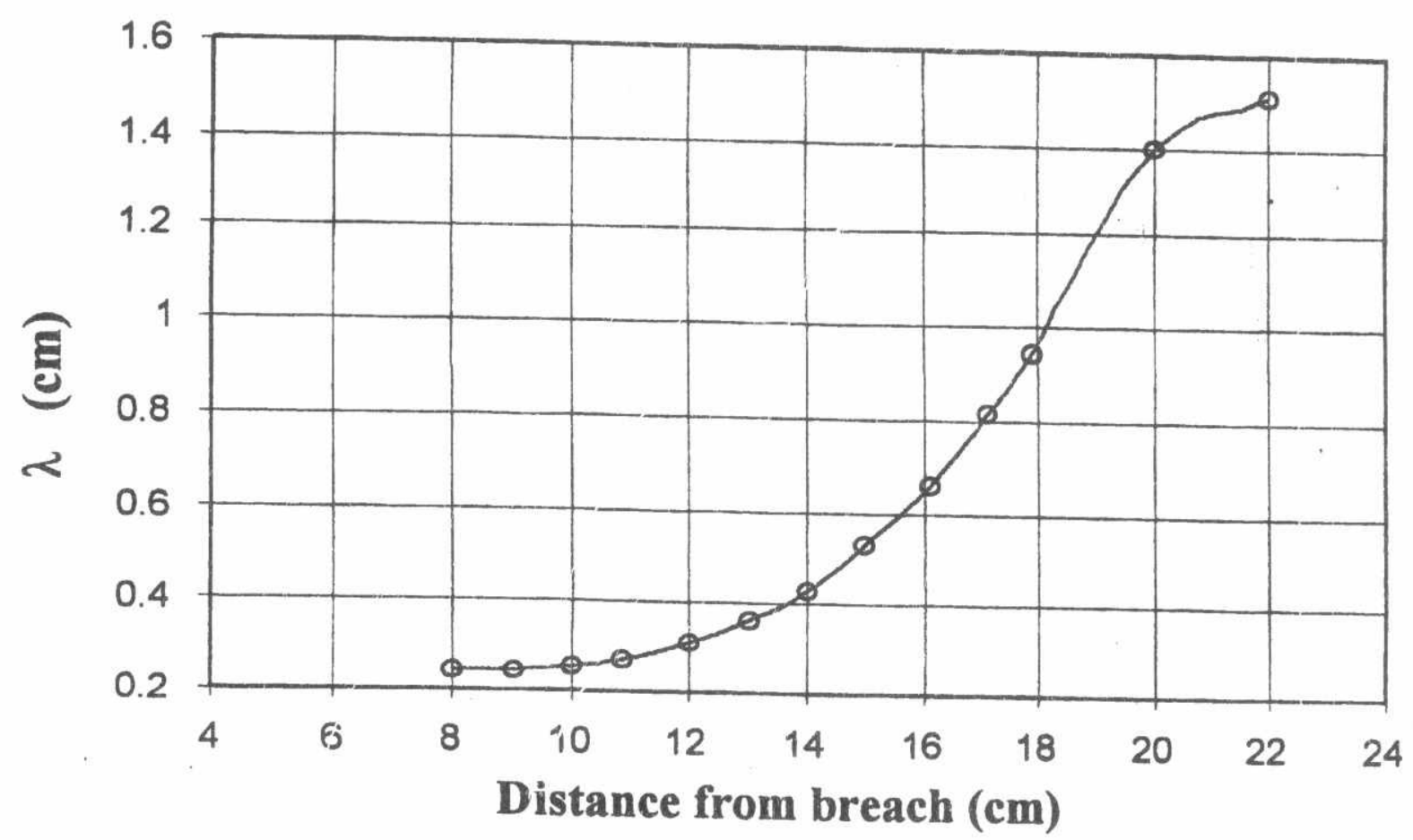

Figure (4) Plasma sheath thickness versus distance.

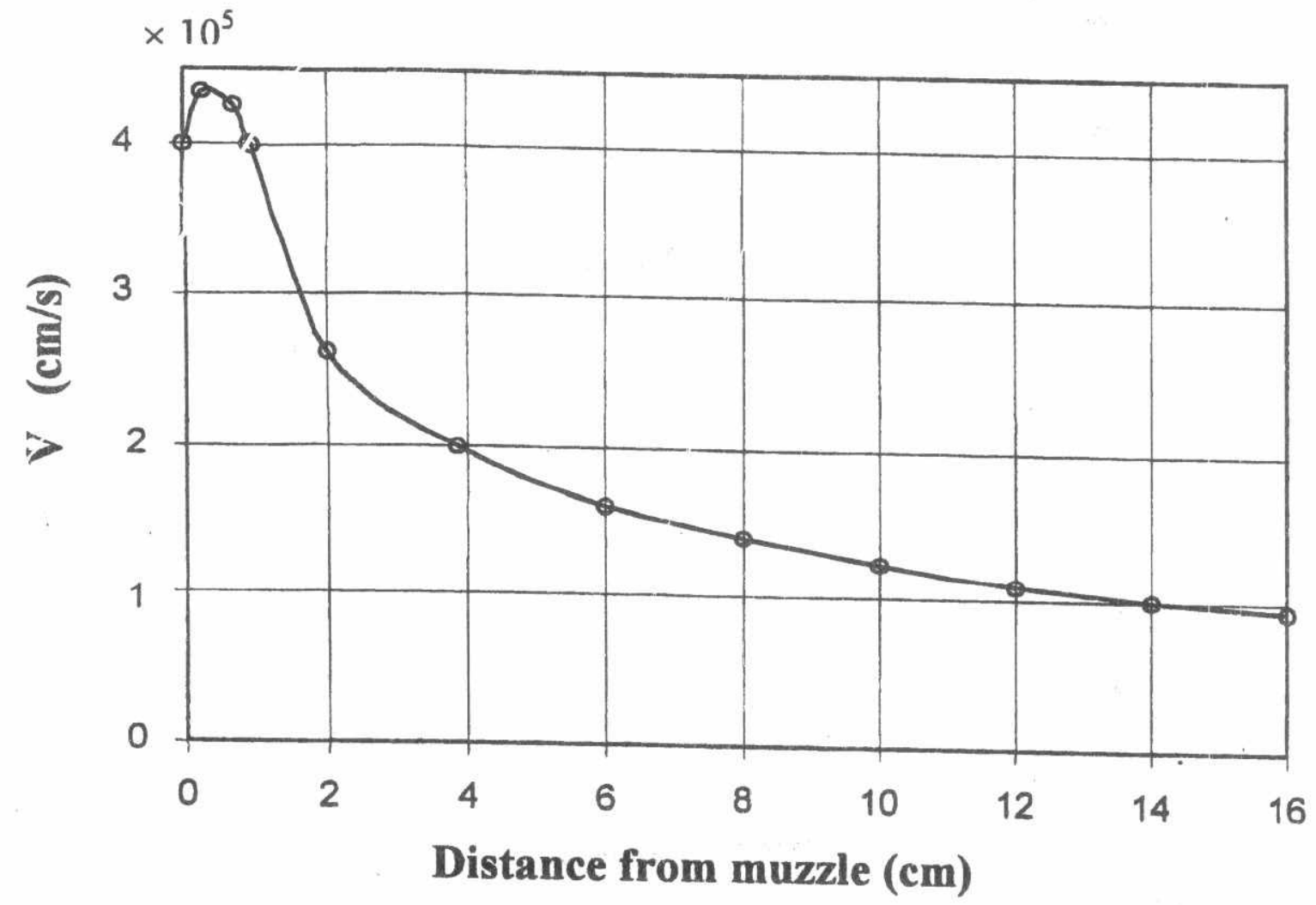

Figure (5) Ejected plasma velocity variation with distance. 


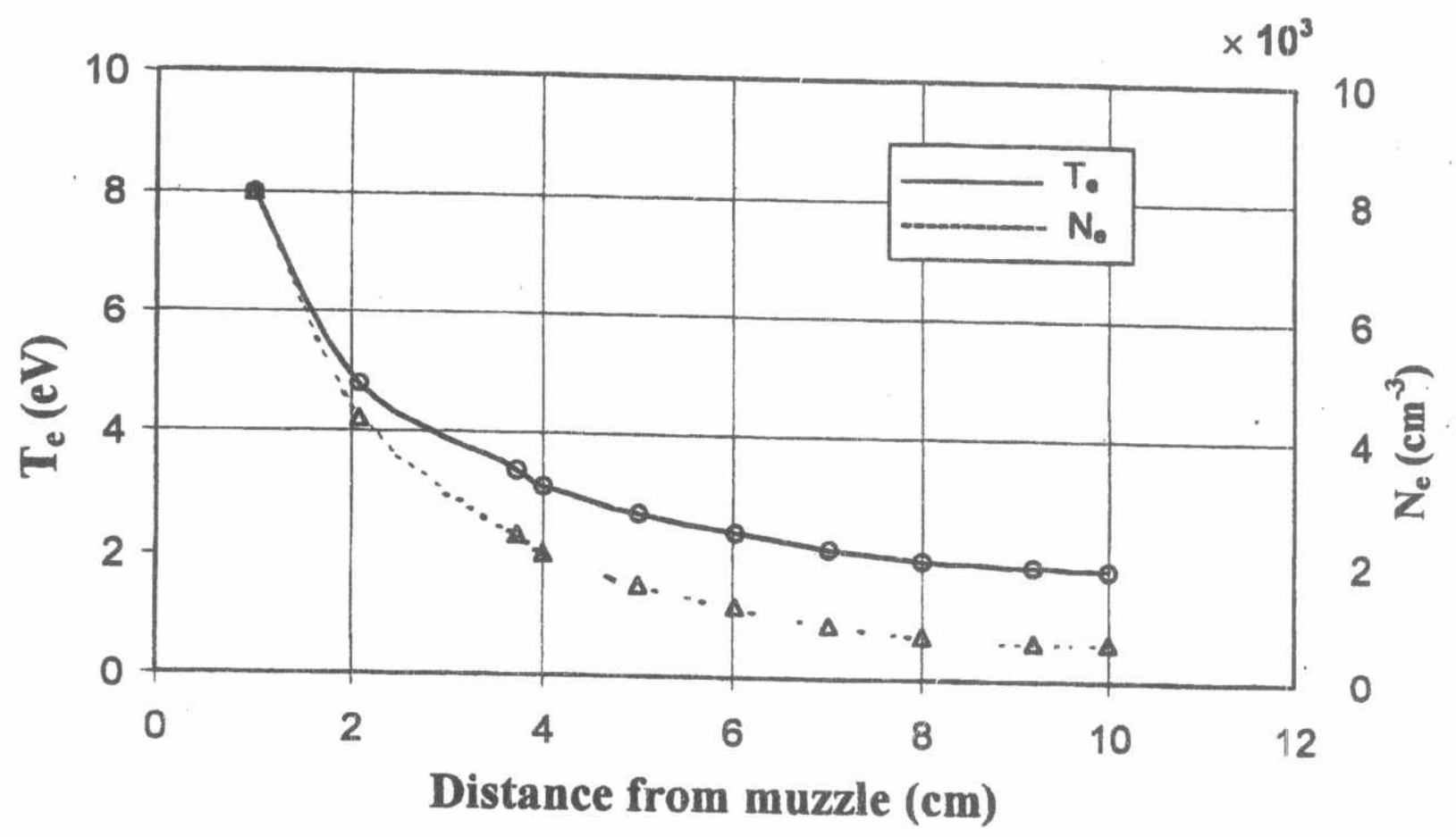

Figure (6) Ejected plasma density and temperature variation with distance. 